\title{
ANALYSIS OF EARTH'S MAGNETIC FIELD CHANGES BY CORRELATION OF ITS PARAMETERS
}

\author{
Jonas Skeivalas $^{1}$, Andrzej Sas-Uhrynowski ${ }^{2}$, Romuald Obuchovski ${ }^{3}$ \\ ${ }^{1}$ Geodezijos ir kadastro katedra, Vilniaus Gedimino technikos universitetas, \\ Saulètekio al. 11, 10223 Vilnius, Lietuva \\ ${ }^{2}$ Institute of Geodesy and Cartography, Modzelewskiego str. 27, 02-679 Warsaw, Poland, \\ ${ }^{3}$ Geodezijos institutas, Vilniaus Gedimino technikos universitetas, \\ Sauletekio al. 11, 10223 Vilnius, Lietuva \\ E-mails: ${ }^{1}$ e-mail: Jonas.Skeivalas@ap.vgtu.lt; ${ }^{2}$ e-mail:zgf@igik.edu.pl; ${ }^{3}$ Romuald.Obuchovski@ap.vgtu.lt \\ Received 1102 2008, accepted 19062008

\begin{abstract}
Changes of Earth magnetic field parameters: field intensity and its components along axes of rectangular coordinates are analyzed in space and time. Data from magnetic observatories Belsk and Hel in Poland were used. Correlation analysis of magnetic field components was applied. Influence of respective field components on changes of geomagnetic field intensity was determined. Shift of space and time factors was used to assess the influence of covariations of geomagnetic field components on changes of covariations of field intensity.
\end{abstract}

Keywords: parameters of Earth's magnetic field and their correlation, changes of covariations of field intensity.

\section{Introduction}

Earth's magnetic field is a constantly changing physical field. The frequency of parameter alterations of this geomagnetic field is not stable - from fractions of a second to year-long of even longer periods, called secular variations. Information about changes of geomagnetic field, which took place between corresponding measurement epochs, are required to process the data of magnetic measurements (Czyszek, A.; Czyszek J. 2002; Marianiuk, Reda 2001; Sas-Uhrynowski et al. 2000; 2002). Such information is gathered in magnetic observatories.

In this paper the covariation of geomagnetic field intensity components and its influence on field intensity covariations changes is analyzed. Correlational dependence between changes of geomagnetic field intensity in time and space was determined by employing the variation of covariation of field intensity components in time. Equations were formed to calculate estimates of covariation matrixes of field intensity components using data of magnetic measurements. Accuracy of respective calculated parameters was assessed.

\section{Covariation of magnetic measurements}

Results of magnetic measurements: intensity of geomagnetic field and its components correlate due to the magnetic field fluctuation. Thus errors of measurement results depend on the magnetic field turbulence.
Covariation between intensities of geomagnetic field $F(t)$ determined during different epochs $t_{i}$ and $t_{s}$ equals (Skeivalas 2007, 2008):

$$
\begin{aligned}
& K\left\{F\left(t_{i}\right), F\left(t_{s}\right)\right\}=M\left\{\delta F\left(t_{i}\right) \cdot \delta F\left(t_{s}\right)\right\}= \\
& M\left\{\delta F\left(t_{i}\right) \cdot h \delta F\left(t_{i}\right)\right\}=h \sigma_{F\left(t_{i}\right)}^{2},
\end{aligned}
$$

here $K, M$ - symbols of covariation and mean, $\delta F\left(t_{i}\right)=$ $F\left(t_{i}\right)-M F\left(t_{i}\right)$ - random error of field intensity due to the influence of magnetic field fluctuation, $\delta F\left(t_{s}\right)=h \delta F\left(t_{i}\right)$, $h$ - coefficient, showing the change of $F(t)$ covariation when transiting from epoch $t_{i}$ to epoch $t_{s} ; \sigma_{F\left(t_{i}\right)}$ - standard deviation. Measurement moments of time are considered as epochs.

Standard deviations $\sigma_{F\left(t_{i}\right)}$ of geomagnetic field intensity $F\left(t_{i}\right)$ can be expressed using standard deviations of its components $F_{x}, F_{y}, F_{z}$. Directions of components $F_{x}$ and $F_{y}$ match the directions of planar coordinate axes, and direction of $F_{z}$ match the vertical direction. Therefore we can write

$$
F(t)=\sqrt{F_{x}^{2}(t)+F_{y}^{2}(t)+F_{z}^{2}(t)},
$$

and when expanding into series we receive 


$$
\begin{aligned}
& F(t)=F_{0}+\frac{F_{x}(t)}{F(t)} \delta F_{x}+\frac{F_{y}(t)}{F(t)} \delta F_{y}+ \\
& \frac{F_{z}(t)}{F(t)} \delta F_{z}+R,
\end{aligned}
$$

or

$$
\delta F(t)=a_{x} \delta F_{x}(t)+a_{y} \delta F_{y}(t)+a_{z} \delta F_{z}(t),
$$

here $F_{0}$ - initial value of $F(t), R$ - sum of non-linear members of the series, which approaches zero; $a_{x}, a_{y}$, $a_{z}$ - values of partial derivatives of $F(t)$ along respective components, calculated by applying known values of the components.

According to formula (2), we receive:

$$
\begin{aligned}
& \sigma_{F}^{2}=\frac{F_{x}^{2}}{F^{2}} \sigma_{F_{x}}^{2}+\frac{F_{y}^{2}}{F^{2}} \sigma_{F_{y}}^{2}+\frac{F_{z}^{2}}{F^{2}} \sigma_{F_{z}}^{2}= \\
& a_{x}^{2} \sigma_{F_{x}}^{2}+a_{y}^{2} \sigma_{F_{y}}^{2}+a_{z}^{2} \sigma_{F_{z}}^{2} .
\end{aligned}
$$

Provided that $\sigma_{F_{x}} \approx \sigma_{F_{y}} \approx \sigma_{F_{z}} \approx \sigma_{0}$, we write $\sigma_{F} \approx$ $\sigma_{0}$, since $a_{x}^{2}+a_{y}^{2}+a_{z}^{2}=1$.

\section{Coordinate expressions of covariations}

Here we will write the formula of covariation of geomagnetic field intensity $F(t)$ using its component expression:

$$
\begin{aligned}
& K\left\{F\left(t_{i}\right), F\left(t_{s}\right)\right\}=K\left\{\delta F\left(t_{i}\right), \delta F\left(t_{s}\right)\right\}= \\
& M\left\{\left(a_{x_{i}} \delta F_{x_{i}}+a_{y_{i}} \delta F_{y_{i}}+a_{z_{i}} \delta F_{z_{i}}\right) \times\right. \\
& \left.\left(a_{x_{s}} \delta F_{x_{s}}+a_{y_{s}} \delta F_{y_{s}}+a_{z_{s}} \delta F_{z_{s}}\right)\right\} \leq \\
& M\left\{\left(\delta F_{x_{i}}+\delta F_{y_{i}}+\delta F_{z_{i}}\right)\left(\delta F_{x_{s}}+\delta F_{y_{s}}+\delta F_{z_{s}}\right)\right\} .
\end{aligned}
$$

Values of coefficients $a_{x_{i}}, a_{y_{i}}, a_{z_{i}}(i=1, \ldots, s)$ are less than one, i.e. $a_{x_{i}}<1, a_{y_{i}}<1, a_{z_{i}}<1$.

Then formula (4) obtains the following form:

$$
\begin{aligned}
& K\left\{F\left(t_{i}\right), F\left(t_{s}\right)\right\} \leq K\left(F_{x_{i}} F_{x_{s}}\right)+K\left(F_{y_{i}} F_{y_{s}}\right)+ \\
& K\left(F_{z_{i}} F_{z_{s}}\right)+2 K\left(F_{x_{i}} F_{y_{s}}\right)+2 K\left(F_{x_{i}} F_{z_{s}}\right)+ \\
& 2 K\left(F_{y_{i}} F_{z_{s}}\right) ;
\end{aligned}
$$

here $K\left(F_{x_{i}} F_{y_{s}}\right)=K\left(F_{x_{s}} F_{y_{i}}\right), K\left(F_{x_{i}} F_{z_{s}}\right)=K\left(F_{x_{s}} F_{z_{i}}\right)$, $K\left(F_{y_{i}} F_{z_{s}}\right)=K\left(F_{y_{s}} F_{z_{i}}\right)$.

By considering, that covariation between components of $F(t)$ is approximately equal, we write:

$$
K\left\{F\left(t_{i}\right), F\left(t_{s}\right)\right\} \leq 9\left(F_{\alpha_{i}}, F_{\alpha_{s}}\right)
$$

here $K\left(F_{x_{i}}, F_{x_{s}}\right) \approx K\left(F_{y_{i}}, F_{z_{s}}\right) \approx \ldots \approx K\left(F_{x_{i}}, F_{y_{s}}\right) \approx$ $K\left(F_{\alpha_{i 0}}, F_{\alpha_{s 0}}\right), \alpha \rightarrow(x, y, z)^{T}$.

We use matrix expression of measurements results of components in $s$ epochs to calculate the estimates of covariations of geomagnetic field intensity $F(t)$ :

$$
\begin{aligned}
& F_{\alpha}=\left(F_{\alpha_{1}}, F_{\alpha_{2}}, \ldots, F_{\alpha_{s}}\right)=\left(F_{\alpha}\left(t_{1}\right), F_{\alpha}\left(t_{2}\right), \ldots, F_{\alpha}\left(t_{s}\right)\right), \\
& F_{\alpha_{i}}=\left(F_{x_{i}}, F_{y_{i}}, F_{z_{i}}\right)^{T}, i=1,2, \ldots, s
\end{aligned}
$$

and

$$
F_{\alpha}=\left(\begin{array}{cccc}
F_{x_{1}} & F_{x_{2}} & \ldots & F_{x_{s}} \\
F_{y_{1}} & F_{y_{2}} & \ldots & F_{y_{s}} \\
F_{z_{1}} & F_{z_{2}} & \ldots & F_{z_{s}}
\end{array}\right) .
$$

Estimate $\bar{K}_{F_{\alpha}}$ of covariation matrix of $F(t)$ component vector $F_{\alpha}$ along coordinates is equal

$$
\bar{K}_{F_{\alpha}}^{\prime}=\frac{1}{s} \delta F_{\alpha} \cdot \delta F_{\alpha}^{T} \text {. }
$$

Here $\delta F_{\alpha_{i}}=\left(\delta F_{x_{i}}, \delta F_{y_{i}}, \delta F_{z_{i}}\right)^{T}, \delta F_{x_{i}}=F_{x_{i}}-\frac{1}{s} \sum_{1}^{s} F_{x_{i}}$, $\delta F_{y_{i}}=F_{y_{i}}-\frac{1}{s} \sum_{1}^{s} F_{y_{i}}, \delta F_{z_{i}}=F_{z_{i}}-\frac{1}{s} \sum_{1}^{s} F_{z_{i}}, i=1,2, \ldots, s$.

Expression (8) in expanded form is written as:

$$
\bar{K}_{F_{\alpha}}^{\prime}=\left(\begin{array}{lll}
K_{x x} & K_{x y} & K_{x z} \\
K_{y x} & K_{y y} & K_{y z} \\
K_{z x} & K_{z y} & K_{z z}
\end{array}\right)=\left(\begin{array}{lll}
K_{11} & K_{12} & K_{13} \\
K_{21} & K_{22} & K_{23} \\
K_{31} & K_{32} & K_{33}
\end{array}\right),
$$

here $K_{x x}=\sigma_{x}^{\prime 2}, K_{y y}=\sigma_{y}^{\prime 2}, K_{z z}=\sigma_{z}^{\prime 2}, \sigma_{x}^{\prime}, \sigma_{y}^{\prime}, \sigma_{z}^{\prime}$ - estimates of standard deviations.

Estimate $K_{F_{\alpha}}^{\prime}$ of covariation matrix of $F(t)$ component vector $F_{\alpha}$ along epochs is calculated as:

$$
K_{F_{\alpha}}^{\prime}=\frac{1}{3} \delta F_{\alpha}^{T} \cdot \delta F_{\alpha} .
$$

Formula (10) in expanded form is written as

$$
K_{F_{\alpha}}^{\prime}=\left(\begin{array}{cccc}
K_{t_{1} t_{1}} & K_{t_{1} t_{2}} & \ldots & K_{t_{1} t_{s}} \\
K_{t_{2} t_{1}} & K_{t_{2} t_{2}} & \ldots & K_{t_{2} t_{s}} \\
\ldots & \ldots & \ldots & \ldots \\
K_{t_{s} t_{1}} & K_{t_{s} t_{2}} & \ldots & K_{t_{s} t_{s}}
\end{array}\right),
$$

here $K_{t_{i} t_{j}}=K\left(F_{\alpha_{i}}, F_{\alpha_{j}}\right)=K\left\{F_{\alpha}\left(t_{i}\right), F_{\alpha}\left(t_{j}\right)\right\}$.

Estimate of covariation of geomagnetic field intensities $F\left(t_{i}\right)$ and $F\left(t_{s}\right)$, considering expressions (6) and (8), is not higher than the sum of members of covariation matrix $K_{F_{\alpha}}^{\prime}(9)$ :

$$
K^{\prime}\left\{F\left(t_{i}\right), F\left(t_{s}\right)\right\} \leq \sum_{i, j=1}^{3} \bar{K}_{F_{\alpha, i j}}^{\prime} .
$$

By applying formulas (1), (3) and (12), we can write

$$
h \sigma_{0}^{2} \leq \sum_{i, j}^{3} \bar{K}_{F_{\alpha, i j}}^{\prime}
$$

and further

$$
h \leq \frac{1}{\sigma_{0}^{2}} \sum_{i, j}^{3} \bar{K}_{F_{\alpha, i j}}^{\prime} .
$$

So the coefficient $h$ indicates the relative change of covariations of geomagnetic field intensity, when transiting from epoch $t_{i}$ to epoch $t_{s}$ during the measurements.

According to the presented formulas, the computer program Kormag. $m$ was developed using operators of software package Matlab. Data from Belsk and Hel magnetic observatory (October, 2000) was used to perform calculations. Results of measurements were registered 


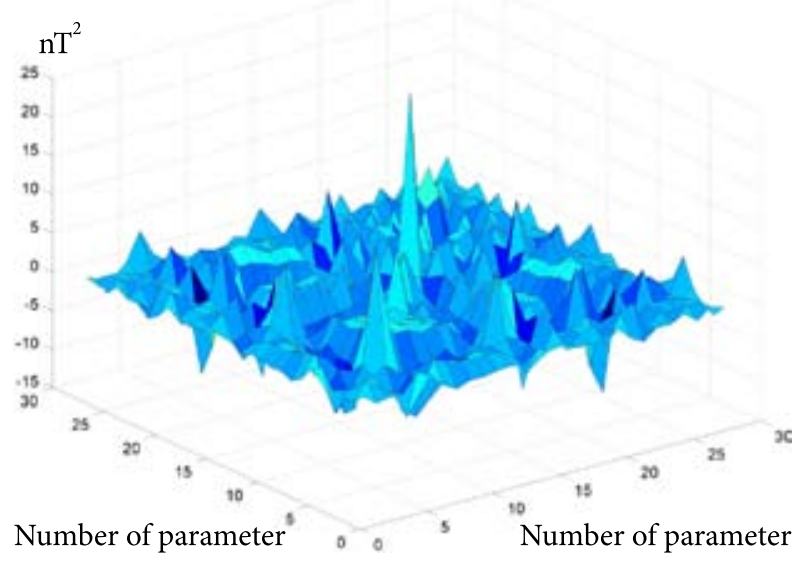

Fig. 1. Graphical view of covariation matrix of $F(t)$ vectors from Belsk2 and Hel30 observatories

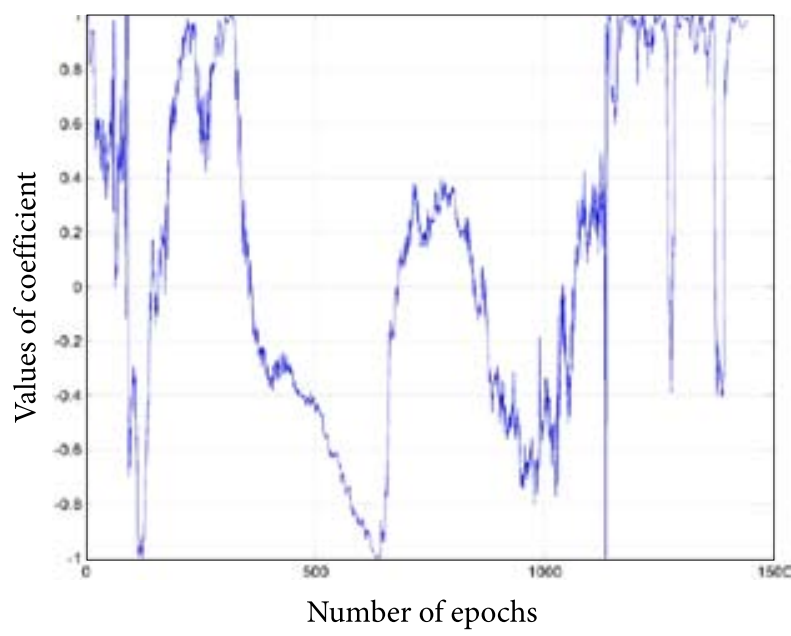

Fig. 2. Epoch-based variation of correlation coefficients of $F_{x}(t), F_{y}(t), F_{z}(t)$ vectors, calculated from $2^{\text {nd }}$ day data from Belsk2 observatory

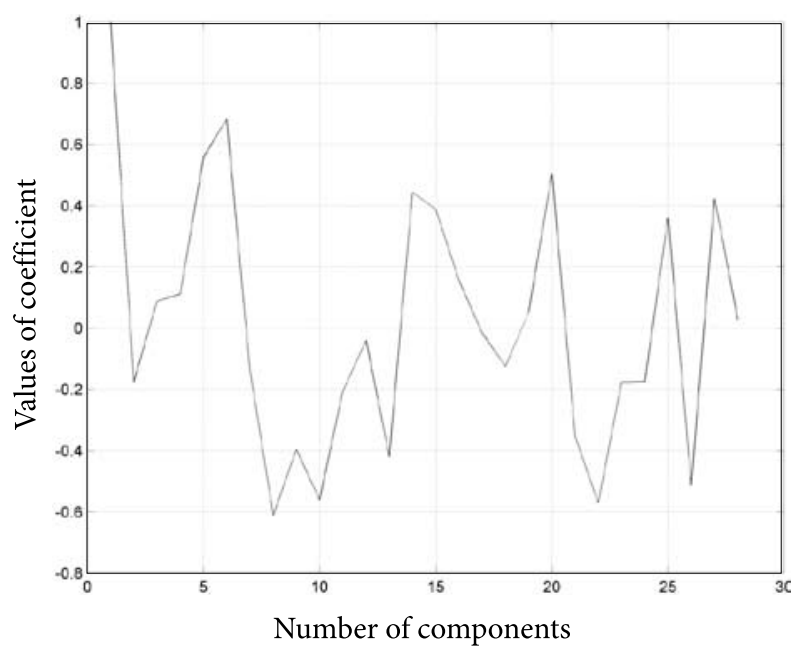

Fig. 3. Values of correlation coefficients of $F(t)$ vectors calculated each 100 epochs using data from Belsk2 and Hel30 observatories

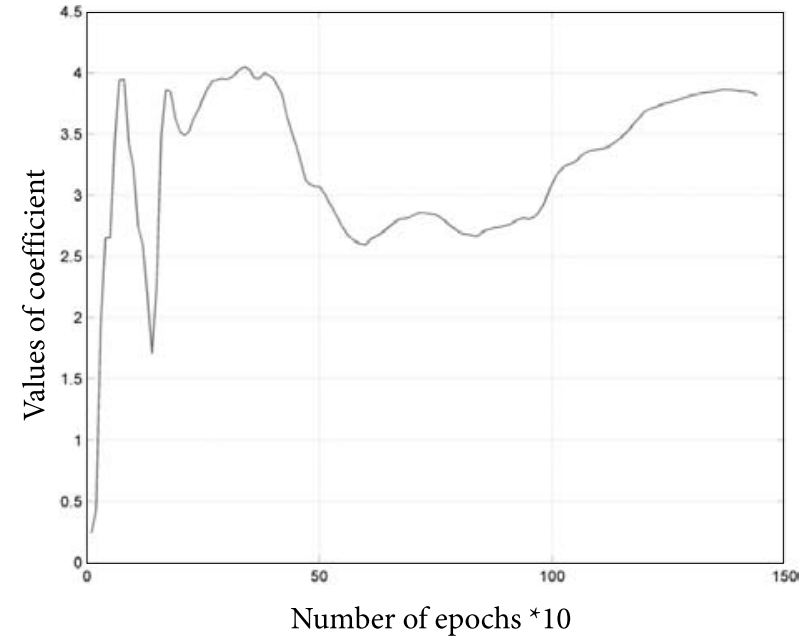

Fig. 4. Values of covariation variation coefficient $h$ of vector $F(t)$ from Hel30 observatory

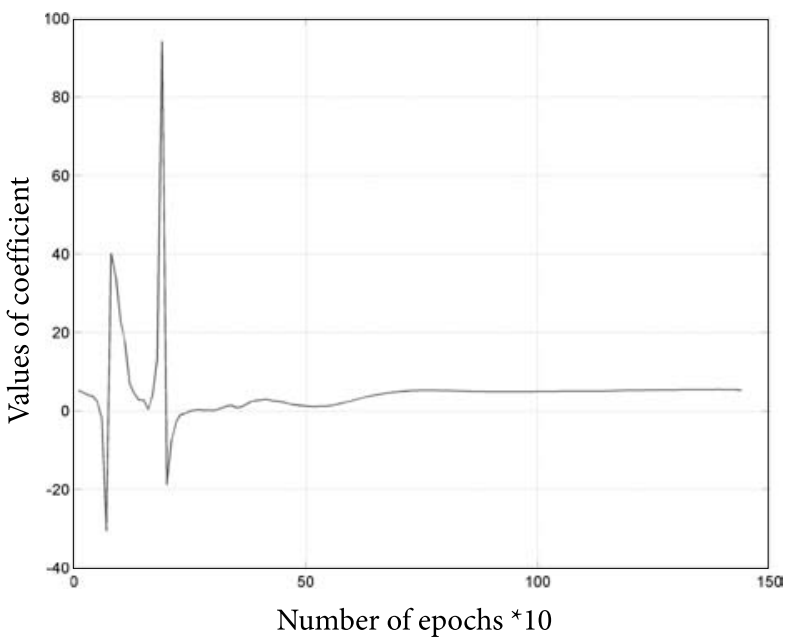

Fig. 5. Values of covariation variation coefficient $h$ of $F(t)$ vectors from data of Belsk2 and Belsk30 observatories

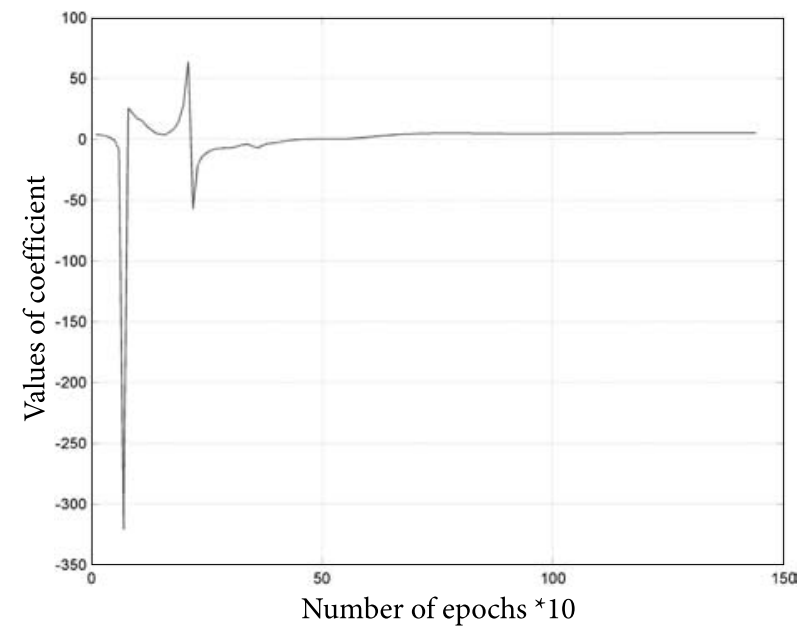

Fig. 6. Values of covariation variation coefficient $h$ of $F(t)$ vectors from data of Belsk2 and Hel30 observatories 
each minute. Summaries of the experiments are shown in diagrams.

General view of covariation matrixes of measurement data $F(t)$ vectors from Belsk2 and Hel2 observatories, when covariations were calculated each interval of 100 epochs (Fig. 1). Numbers included in the names of observatories indicate days of a month.

Epoch-based variation of correlation coefficients of $F_{x}(t), F_{y}(t), F_{z}(t)$ vectors, calculated from one day data from Belsk 2 observatory is in Fig. 2.

Values of correlation coefficients of $F(t)$ vectors calculated each 100 epochs using data from Belsk2 and Hel30 observatories is in Fig. 3.

Values of covariation variation coefficient $h$ of $F(t)$ vectors from observatory Hel30, calculated according to covariations of respective components $F_{x}(t), F_{y}(t)$ and $F_{z}(t)$ each 10 epochs, are in Fig. 4 .

Values of covariation variation coefficient $h$ of $F(t)$ vectors from data of Belsk2 and Belsk30 observatories, calculated according covariations of respective components $F_{x}(t), F_{y}(t), F_{z}(t)$ each 10 epochs are in Fig. 5.

Values of covariation variation coefficient $h$ of $F(t)$ vectors from data of Belsk2 and Hel30 observatories, calculated according covariations of respective components $F_{x}(t), F_{y}(t), F_{z}(t)$ each 10 epochs are in Fig. 6.

\section{Conclusions}

1. The results of magnetic field parameter measurement in single epochs strongly correlate due to turbulence of magnetic field and measurement errors, therefore covariation matrix should be used when processing them.

2. Formulas were derived for determining relative change of covariations of geomagnetic field intensity $F(t)$, when transiting from one epoch to other during measurements, using covariations of $F(t)$ components $F_{x}(t), F_{y}(t), F_{z}(t)$, determined according to single epochs.

3. It was found, according to the results of investigation, that the relative change of covariations of geomagnetic field parameter $F(t)$ of both observatories Belsk and Hel, according to epochs of own observatory, vary in the range of $1,5<h<$ 4 , when this change is determined according to $F(t)$ components.

4. Relative change of covariations of magnetic field parameter $F(t)$, which was determined according to the data of different days of single observatory and according to the data of different observa- tories is close to zero $(h \approx 0)$, when components $F_{x}, F_{y}, F_{z}$ are used to calculate $F(t)$. However, values of coefficient $h$ significantly vary in initial epochs, apparently due to the small amount of available data.

\section{References}

Czyszek, A.; Czyszek, J. 2002. Results of geomagnetic observations, Hel, 2000, Publications of the Institute of Geophysics, Polish Academy of Science, Warszawa.

Marianiuk, J.; Reda, J. 2001. Results of geomagnetic observations, Belsk, 2000, Publications of the Institute of Geophysics, Polish Academy of Science, C-79 (328): 110.

Sas-Uhrynowski, A.; Karatayev, H.; Mroczek, S.; Karagodina, O. 2000. Badania zmian wiekowych pola geomagnetycznego na terytorium Polski I Białorusi [Research of the secular variation of the geomagnetic field on Polish and Belarus territory], Prace IGiK XLVII(100): 25-34.

Sas-Uhrynowski, A.; Mroczek, S.; Abromavičius, R.; Obuchowski, R. 2002. New Investigations of Lithuania, Geodezija ir kartografija [Geodesy and Cartography] 28(3): 88-94.

Skeivalas, J. 2007. Koreliacinè analizė jonosferos ittakai GPS matavimams nustatyti [Practice of correlation analysis for determination of ionospheric influence on GPS measurements], Geodezija ir kartografija [Geodesy and Cartography] 33(4): 98-101.

Skeivalas, J. 2008. GPS tinklų teorija ir praktika [Theory and Practice of GPS Networks]. Vilnius: Technika. 288 p.

Jonas SKEIVALAS. Prof, Doctor Habil. Vilnius Gediminas Technical University. Dept of Geodesy and Cadastre, Sauletekio al. 11, LT-10223 Vilnius, Lithuania. Ph +370 52744 703, Fax +370 52744 705, e-mail: jonas.skeivalas@ap.vgtu.lt.

Author of two monographs and more than 150 scientific papers. Participated in many intern. conferences and research visits to the Finish Geodetic Institute.

Research interests: processing of measurements with respect to tolerances, adjustment of geodetic networks.

Andrzej SAS-UHRYNOWSKI. Prof, Doctor Habil. Institute of Geodesy and Cartography, Modzelewskiego str. 27, 02-679 Warsaw, Poland, Ph +48 02232919 13, e-mail: zgf@igik.edu.pl

Research interests: geomagnetic field, gravimetry.

Romuald OBUCHOVSKI. Master of science. Vilnius Gediminas Technical University. Dept of Geodesy and Cadastre, Sauletekio al. 11, LT-10223 Vilnius-40, Lithuania ( $\mathrm{Ph}+3705$ 2744703, Fax +370 5 2744705), email: romuald.obuchovski@ gmail.com

Research interests: geomagnetic field, gravimetry. 